\section{Stimulus generalization and discrimination}

\section{along the click-frequency (flutter) continuum in pigeons*}

\author{
G. WILLIAM FARTHING, University of Maine, Orono, Maine 04473 \\ and \\ ELIOT HEARST, Indiana University, Bloomington, Indiana 47401
}

Before tests for click-frequency generalization, pigeons had been reinforced for keypecks during one click frequency $(\mathrm{S}+)$. Some $\mathrm{Ss}$ received $\mathrm{S}+$ training only, whereas other Ss also received unreinforced (S-) trials, during which the clicks were either absent (Experiments 1-3) or presented at some other frequency (faster or slower than $S+$ : Experiment 4 ). When training included $S+$ trials only, birds responded approximately equally to all generalization test frequencies $(0.0$ to 53.5 pulses/sec, pps). Most Ss that had received both $\mathrm{S}+$ and $\mathrm{S}$ - training trials responded fastest not during $S+$ but during click frequencies even further away from $\mathrm{S}-$ along the click-frequency dimension (peak shift). Complex bimodal gradients were obtained after training with $S+(1.6 \mathrm{pps})$ vs $\mathrm{S}-(0.0 \mathrm{pps})$; maximal responding generally occurred near $S+$ and at approximately $14.2 \mathrm{pps}$. Among other factors, the "nonorthogonality" of click absence $(0.0 \mathrm{pps})$ to the click dimension seems crucially involved in producing these complex effects.

Because of their excellent eyesight, pigeons have been widely used in experiments on visual discrimination learning and stimulus generalization. There has been considerably less pigeon research with auditory stimuli. Unlike typical findings obtained from avians with such visual dimensions as wavelength or brightness [see, for example, Blough (1959) and Riley and Leuin (1971)], manipulations of the frequency or intensity of a tone present during reinforcement do not seem to affect the operant behavior of pigeons unless Ss have been given explicit training to discriminate between two or more different auditory cues. For example, Jenkins and Harrison (1960) obtained approximately equal responding (keypecking) to test tones ranging from 300 to $3,500 \mathrm{~Hz}$ after training in which a 1,000-Hz tone was present during all pecking periods. However, following training on a successive discrimination in which pecks during a $1,000-\mathrm{Hz}$ tone were reinforced but pecks during the absence of the tone

\footnotetext{
*Experiments 1 and 2 were conducted at the University of Missouri, Columbia, with the support of NIMH Grant MH 12120 to E.H. Experiments 3 and 4 were performed at the University of Maine. The latter two experiments and preparation of this report were supported by NIMH Grant MH 18290 to G.W.F. at the University of Maine and by Grant MH 19300 to E.H. at Indiana University. The authors thank Charles Hayden, Minnie B. Koresko, Tom Nelson, Mike Opuda, and Sharron Taus for assistance in running the Ss. Some of the findings were presented at the 1968 meeting of the Midwestern Psychological Association in Chicago. Reprints may be obtained from the first author at the Department of Psychology, University of Maine, Orono, Maine 04473.
}

were not reinforced, those Es obtained steeply sloped gradients around the 1,000-Hz positive stimulus. Similar results have been observed on the tone-intensity continuum (Malott \& Malott, 1967)

Control of pigeon behavior by the auditory dimension of click rate (or flutter frequency, as it was called by Miller and Taylor, 1948) has not been previously investigated to our knowledge. As the rate of interruption of suprathreshold click or noise bursts increases, human Ss usually report an increase in loudness as well as a change in the subjective quality of the stimulus-from a mere succession of single pulses at very low frequencies, to a sound having a pitch character ("buzz") at intermediate frequencies, to a complex continuous noise at very high interruption rates (Flanagan \& Guttman, 1960; Miller \& Taylor, 1948). Furthermore, in humans there is another type of effect-a broad minimum in the absolute threshold curve for interrupted white noise between 2 and 10 pulses per second (pps) (see Pollack, 1951). Therefore, studies of click-frequency generalization and discrimination in lower organisms might yield rather complex functions, indicating several interactive effects along this continuum.

There has been some previous work with animals involving variation of click-frequency stimuli. Hearst (1965) reported differential responding along the click-frequency dimension in rats following explicit discrimination training between two click frequencies, but little or no differential responding following simple [variable-interval (VI) reinforcement] training with only one click frequency. Winograd (1965) used the click dimension to study maintained generalization gradients of conditioned suppression in rats. Some other studies of click variation in rats include Crites, Harris, Rosenquist, and Thomas (1967), Hendry, Switalski, and $Y$ a rezower (1969), and Mostofsky, Shurtleff, and Margolius (1964). Of course, Pavlov (1927) occasionally employed metronome beats as differential CSs in dogs. Sidman (1961) examined click-frequency generalization gradients in monkeys as a function of various parameters of shock-avoidance conditioning and generalization-testing procedures.

The present set of experiments is intended to provide some basic data on the shape of click-frequency gradients of generalization in individual pigeons after "nondifferential" training, in which only one click value is present during performance of the operant response, and after explicit discrimination training. The experiments are admittedly empirically oriented, and thus they may be mainly of use to Es interested in employing the click dimension for generalization work with pigeons. However, we hope that some of the unexpected but consistent characteristics of the pigeon's generalization gradients will prove provocative and valuable for theoretical analyses of flutter perception and other auditory phenomena in humans and animals.

\section{EXPERIMENT 1}

In this experiment, pigeons were rewarded with grain on a VI schedule in the presence of one click frequency (S+: $1.6 \mathrm{pps}$ for some Ss, $9.4 \mathrm{pps}$ for other Ss). Besides these positive trials, some birds also had trials with the clicker turmed off (i.e., a click frequency of $0.0 \mathrm{pps}$ ), during which pecking was not rewarded (S-). Subsequently, generalization tests along the click-frequency continuum were administered to all Ss during extinction.

\section{Method}

Subjects. Fifteen experimentally naive female White Cameaux pigeons (5-8 years old) were maintained at $75 \%$ of their free-feeding body weights.

Apparatus. The birds were trained in a standard Grason-Stadler pigeon test chamber equipped with a houselight, food magazine, speaker (mounted on the lower left side of the intelligence panel), and response key that was transilluminated with red light during all pecking periods. 

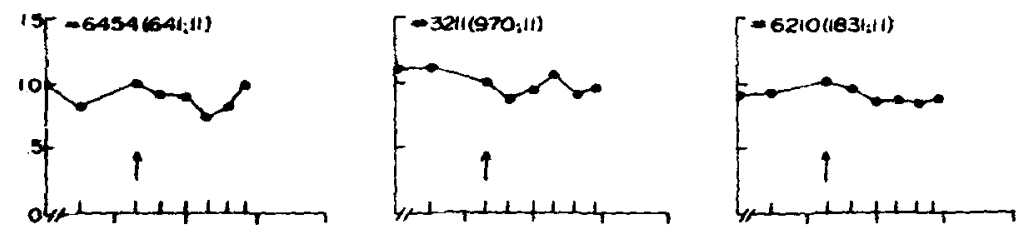

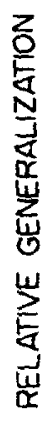
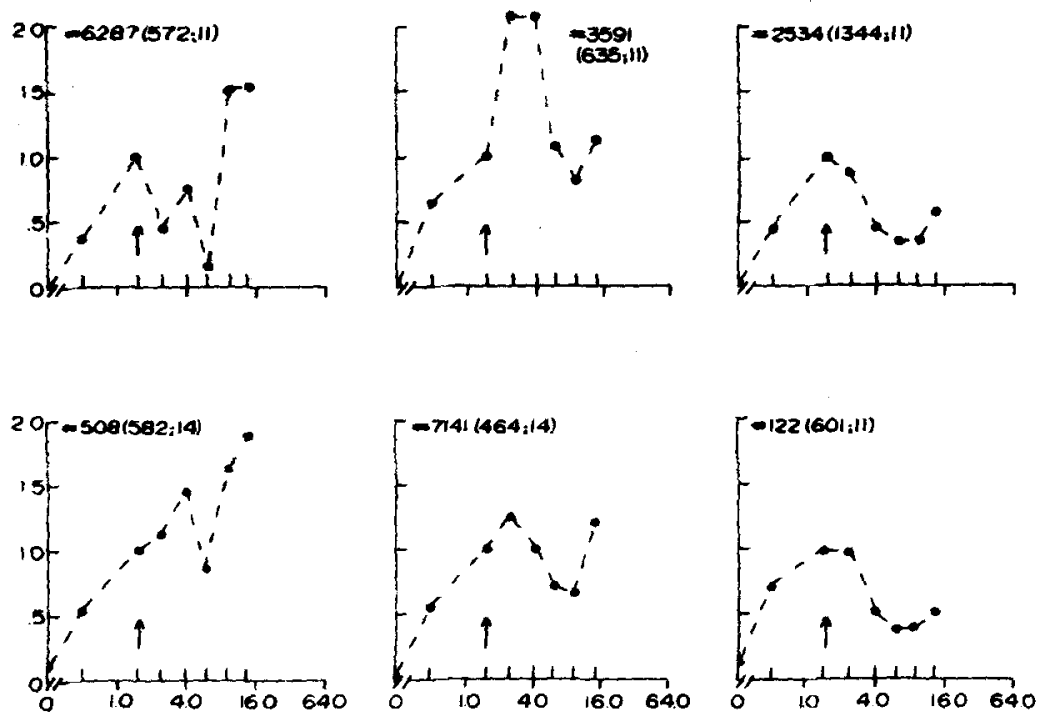

\section{CLICK FREQUENCY (PPS)}

Fig. 1. Relative generalization gradients for birds trained with $S+(1.6 \mathrm{pps})$ in Experiment 1. Birds in the top row received nondifferentinl training, with the 1.6-pps click continuously present during pecking periods; birds in the bottom two rows were txained on a successive discrimination with $\$$ clicks (0.0 pps). For each $S$, the first number in parentheses is the total number of pecks during the test and the second number is the number of training sessions received by that bird prior to the test. Upward arrows indicate the S+ value.

Reinforcement consisted of 5 -sec
access to mixed grain.
Click stimuli were produced by a
Foringer click generator (Model 1293).
The eight frequencies used in this
experiment were $0.0,0.5,1.6,2.6$,
$4.0,6.4,9.4$, and 14.2 pps. The clicks
had a rectangular waveform, measured
at the $45-0 h m$ impedance Quam 4 -in.
dynamic loudspeaker. Their physical
intensity (approximately 106 dB SPL,
measured with a General Radio Type
1551-C sound level meter placed about
8 cm in front of the response key) and
their duration (approximately 6 msec,
with a rise time of 0.1 msec and a
decay time of 0.6 msec) changed very
little as click rate was varied. The
clicks were superimposed on a
continuously present white noise of
91 dB SPL (overall level), measured
about 8 cm in front of the response
key. The noise was produced by a
Grason-Stadler Model $901 \mathrm{~B}$ white
noise generator, which generates
frequencies between 70 and

$10,000 \mathrm{~Hz}$; total harmonic distortion at midrange is stated by the manufacturer to be less than $1 \%$. Two human judges reported informally that the clicking stimulus seemed to change from a succession of single pulses to a "buzz" at around 25-30 pps.

Procedure. All birds were trained initially to peck the response key by the method of successive approximations, and were then given 30 continuous reinforcements (CRF) per day for 2 successive days. The click frequency which was to be used as $S+$ for a given bird remained on throughout this preliminary training.

Six birds then received so-called "nondifferential" training for 11 sessions. Each session consisted of 45 30 -sec periods, alternated with $10-\mathrm{sec}$ blackouts during which the click stimulus and the keylight and houselight were turned off. Birds hardly ever peck in the dark, but any pecks that did occur during the blackouts were not reinforced. During stimulus periods, pecks at the key were reinforced on a $1-\mathrm{min}$ VI schedule. The click frequency present during these periods was 1.6 pps for three $\mathrm{Bs}$ and $9.4 \mathrm{pps}$ for three $\mathrm{Ss}$.

Immediately after initial shaping and CRF, nine other birds began training on a successive discrimination. Each session consisted of a nonsystematic mixture of 45 periods $(S+)$ in which pecks were reinforced on 1-min VI achedule and 90 periods (N-) in which peck were not reinforeed. The $\mathbf{S t}$ and $\mathrm{s}$ periods were 30 eec long and were weparated by 10-eec blackouts. The binds were trained for at least 11 senions on this diccrimination and until they met a criterion of two consecutive semions, during which the reaponse rate in 8 wan not more than $25 \%$ of the rate in S+. The 8+ was 1.6 ppe for six birds and $9.4 \mathrm{pps}$ for three birds. The $8-$ was the abeence of clicks (0.0 ppe) for all nine discrimination-trained Se.

On the day after the last training semion, each $\mathbf{S}$ was given a brief warm-up of additional training with reinforcement in $\mathrm{S}+(15 \mathrm{~S}+\mathrm{s}$ for the nondifferentially trained $\mathrm{Ss}$ and $15 \mathrm{~S}+\mathrm{s}$ and $30 \mathrm{~g}-\mathrm{s}$ for the diecrimination trained Ss), followed by a generalization test in extinction. The test consisted of eight different click frequencies, presented once in each of 10 randomized blocks. All Ss had the seme sequence of the different click frequencies, except for Bird No. 7141. Test stimuli were 30 sec long and were separated by 10 rec blackouts. The $E$ recorded the number of keypecks during each test stimulus period.

\section{Results and Discussion}

Relative generalization gradients for individual $\mathbf{S}$ are shown in Figs. 1 and 2. Figure 1 presents the gradients for birds trained with S+ (1.6 pps) and Fig. 2 for birds with S+ (9.4 pps). Relative generalization was scaled by assigning a value of 1.0 to the total number of test responses at $S+$ and then converting response levels at each of the other test values to ratios of the response level at $S+$. The abscissa displays the various click frequencies on a logarithmic scale, with $0.0 \mathrm{pps}$ placed an arbitrary distance below the 0.5 pps value.

The gradients of the birds given nondifferential training (top rows of Figs. 1 and 2) showed little or no evidence of specific control by the click frequency present during training. Birds 6210 and 3084 yielded gradients with a peak at $S+$, but these gradients were very shallow. Bird 3556, trained with 9.4 pps as $S+$, pecked more during presentations of the higher click frequencies than during the lower ones, but the peak of its gradient was not at $S+$ 
Every bird that had been trained to discriminate between two different frequencies (S- was 0.0 pps for all these birds) showed cleax effects of variations in click frequency during testing. The gradients of the six birds trained with S+ (1.6 pps) could generally be described as bimodal (Fig. 1, bottom two rows). All six birds had an initial peak at or near the St value. In three Ss (Nos. 3591, 508, and 7141 , more responding actually occurred at a value one or two stepe above $\mathbf{S}+$ than at $\mathbf{S}+$ iteelf-an effect that is apparently an example of the phenomenon of "peak shift," which has been demonstrated many timos along the visual wavelength continuum in pigeons following discrimination training with two different wavelengths (see Terrace, 1966). As click frequency was increased even higher, responding first decreased and then increased again in all $\mathrm{Ss}$ to a second peak at the highest test frequency (14.2 pps). This second mode was especially prominent in Birds 6287, 508, and 7141. In the other three birds, responding was higher at $14.2 \mathrm{pps}$ than at adjacent frequencies, but this second mode was not as prominent as the first.

In all three birds given discrimination training with $9.4 \mathrm{pps}$ as St (Fig. 2, bottom row), responding tended to increase as click frequency increased. The gradients of two of these birds had their peak at the highest click frequency (14.2 pps), which was the only test value above $S+$ for these birds.

Therefore, explicit discrimination training appears necessary to establish click-frequency control of operant (keypecking) behavior in pigeons. Furthermore, this experiment demonstrates that peak shift will occur along an auditory dimension in pigeons; the shift was obtained in more than half the discrimination $S_{s}$ in Figs. 1 and 2. We were puzzled, however, by the bimodal gradients consistently observed in birds trained to discriminate $S+(1.6 \mathrm{pps})$ from the absence of clicks. This complex generalization pattern suggested that at least two kinds of effect were interacting along the click dimension. Experiments 2 and 3 were mainly attempts to systematically replicate and explore this bimodality by changing various aspects of the training and testing procedures.

\section{EXPERIMENT 2}

The occurrence of gradient modes at click frequencies above $S+$ in the $S+$ (1.6 pps) vs $\mathrm{S}-(0.0 \mathrm{pps})$ Ss of Experiment 1, as well as the direct relationship between generalization responding and click frequency in the other $(\mathrm{S}+=9.4 \mathrm{pps})$ discrimination Ss
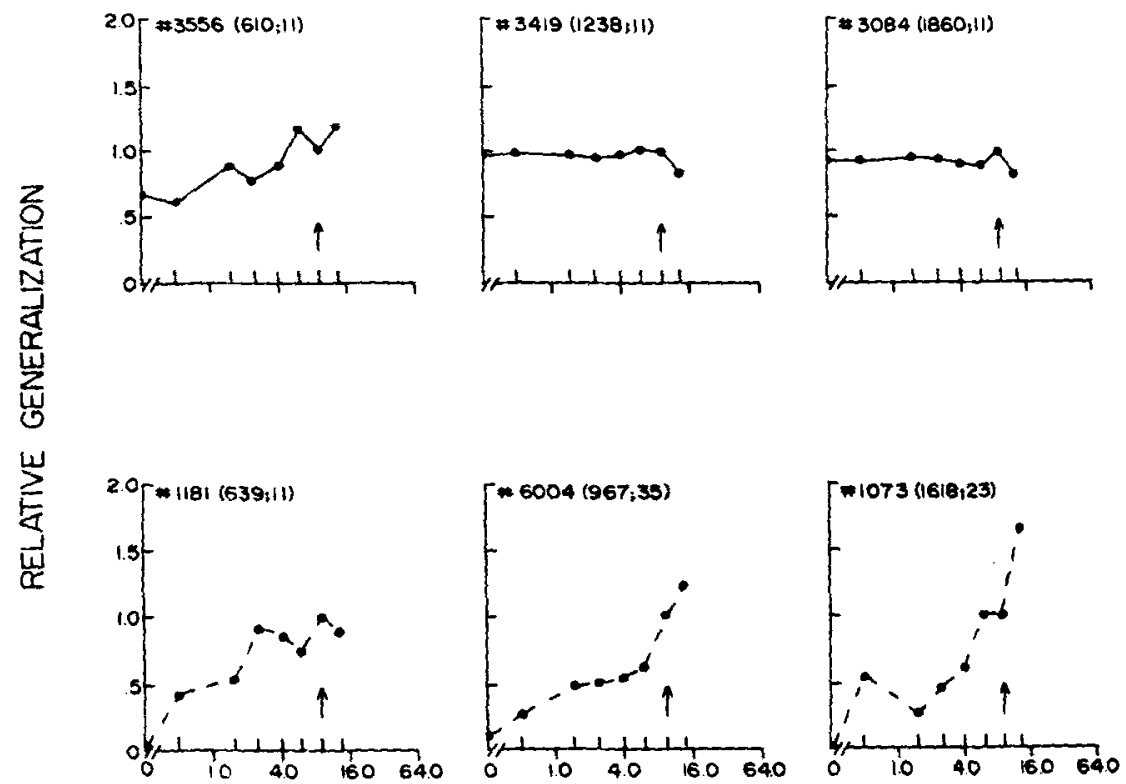

CLICK FREQUENCY (PPS)

Fig. 2. Relative generalization gradients for birds trained with $S+(9.4 \mathrm{pps})$ in Experiment 1. Birds in the top row received nondifferential training; birds in the bottom row were trained on a successive discrimination with $S-$ the absence of clicks. Numbers in parentheses are as in Fig. 1.

(Fig. 2), bring to mind the phenomenon that Hull (1949) labeled "stimulus intensity dynamism" (see Gray, 1965, for a review). Several workers have noted that the mechanisms underlying flutter perception seem to resemble those underlying intensity judgments with an uninterrupted auditory stimulus (cf. Pollack, 1952; Stevens \& Shickman, 1959). Furthermore, as pointed out earlier, human Ss usually do report loudness increments when the frequency of intermittent suprathreshold clicks or noises is increased. If our findings are viewed in the light of these intensity-related effects (see also Winograd, 1965), then the hypothesis proposed by Perkins (1953) and Logan (1954) to explain stimulus intensity dynamism may well apply to the present situation. Perkins and Logan attributed the greater conditioned response strength at test intensities higher than $\mathrm{S}+$ to the interaction of an excitatory generalization gradient centered at $\mathbf{S}+$ and an inhibitory gradient centered at the nonreinforced, zero-intensity stimulus.

Two implications of the Perkins-Logan hypothesis seem of particular interest in connection with the data of Experiment 1 . First, greater responding at values above $\mathrm{S}$ t should occux only after explicit discrimination training; no inhibitory gradients could be established if $\mathbf{S}-$ trials were not presented during training. The results of Experiment 1 support this prediction, since there was very little, if any, evidence of greater response strength at the higher click frequencies in the nondifferentially trained Ss-even though their training may actually have involved some unintended discrimination learning, due to the use of blackout periods during which the click generator was turned off and reinforcement was not available (see Experiment. 3 for an evaluation of this aspect of the procedure). Confirming the Perkins-Logan general approach, most of the discrimination Ss in Figs. 1 and 2 did show, in one form or another, relatively more responding at the higher than at the lower click frequencies.

A second relevant implication of the Perkins-Logan hypothesis concerns the general form of gradients along an intensitive continuum. Rephrased, their hypothesis views greater responding at values above $\mathbf{S}+$ as just another example of the phenomenon of peak shift; if $S$ receives discrimination training in which $S-$ is of a lower intensity than $S+$, subsequently obtained gradients should be peaked at a test value above St. However, as intensity is increased even further, responding should decrease due to a decrement in 

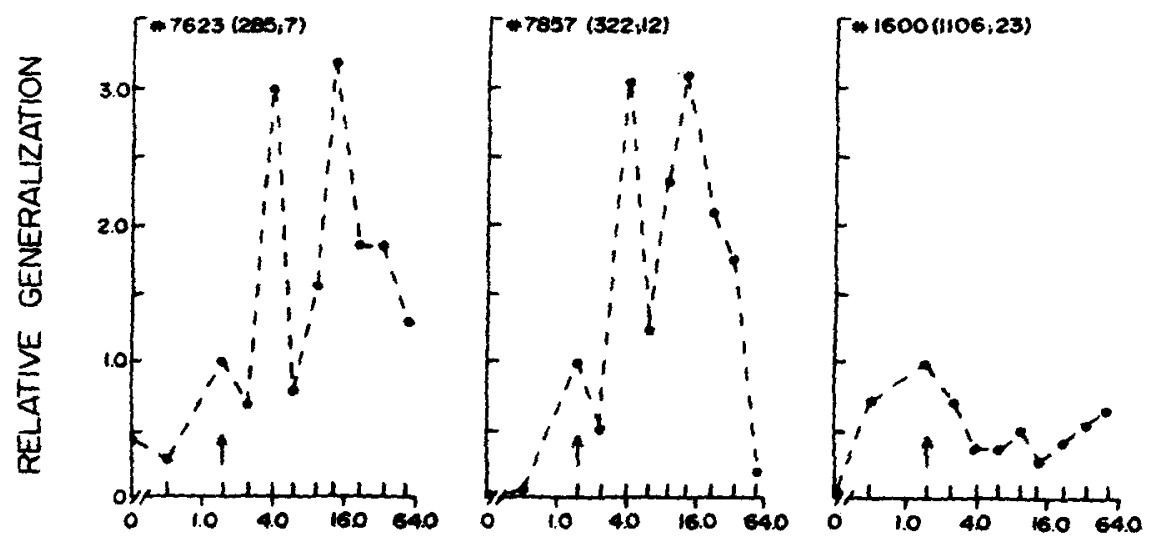

CLICK FREQUENCY (PPS)

Fix. 3. Relative generalization gradients for birds trained on the ancesenive discrimination, $S+(1.6 \mathrm{pps}) \mathrm{vs} S-(0.0 \mathrm{pps})$ in Experiment 2 . Numbers in parentheses are as in Fis. 1.

excitatory generalization. This prediction was supported in a study by Malott and Malott (1967) with pigeons trained on a tone-intensity discrimination; peak shift typically occurred, but responding eventually declined at much higher intensity values than S+. Ernst, Engberg, and Thomas (1971) recently obtained analogous results along the visual-intensity dimension.

Although the increase-declinerecovery pattern of responding at values above $S+$ in the $S+(1.6 \mathrm{pps})$ group is not easily explained by simple application of the Perkins-Logan hypothesis, other characteristics of the gradients of the discrimination $\mathrm{Ss}$ in Figs. 1 and 2 generally do agree with the hypothesis. One further way of evaluating it would be to test some frequencies even higher than the ones employed in Experiment 1. If the second peak at approximately 14.2 pp in Fig. 1 is mainly the result of some interaction between complex excitatory and inhibitory gradients, responding may well decline at higher values, due to a decrement in excitatory generalization. Therefore, in Experiment 2, new birds were trained on the $S+(1.6 \mathrm{pps})$ vs $S-$ (0.0 p ps) discrimination of Experiment 1, but three additional click frequencies, all higher than the click frequencies employed in Experiment 1, were included in the generalization test.

\section{Method}

Subjects and apparatus. The Ss were hree naive pigeons of the same kind $s$ in Experiment 1. The treatment of he Ss and the details of the apparatus ere also the same as in Experiment 1. 1 addition to the eight click equencies used in Experiment 1, the generalization test included click frequencies of 23.0, 36.0, and 63.5 pps.

Procedure. Each $\mathbf{S}$ was trained on the successive discrimination $8+$ (1.6 pps) vs $\mathrm{g}-(0.0 \mathrm{pps})$ until it met a criterion of two consecutive sessions in which response rate in $\mathbf{S}$ was not more than $25 \%$ of the rate in $S+$. On the following day, a generalization test was administered which included 11 different click frequencies, presented once in each of 12 randomized blocks. Experiment 1 had been marred by the fact that, as noted earlier, the same sequence of test values was used for 14 of the $15 \mathrm{Ss}$ (due to a misunderstanding between the authors and the person running the tests). In Experiment 2, a different sequence was used for each $S$. Other aspects of the procedure were the same as in Experiment 1.

\section{Results and Discussion}

Relative gradients for the three individual Ss are shown in Fig. 3. As in Fig. 1, the gradients were nonmonotonic and generally bimodal. In two of the three Ss, a pronounced peak shift was exhibited to a value somewhat higher than S+, as well as a second peak at an even higher value (14.2 pps). In every $S$, responding was weaker at the three new (highest) test frequencies than at the peak (s) of the gradients. This finding could be considered to support the general analysis offered by Perkins and Logan (i.e., it may reflect a decrement in excitatory generalization).

\section{EXPERIMENT 3}

Experiment 3 was an attempt to analyze further the complex gradients displayed by the $\mathrm{S}+(1.6 \mathrm{pps})$ vs $\mathrm{S}-$ (0.0 pps) birds in Experiments 1 and
2. The robustnes of those effects was tested by changing the procedure in several major ways from that used in the prior experiments. In Experiment 3, blackouts were eliminated from the procedure, and during discrimination training a "correction" contingency was included, such that $\&$ did not end until 30 sec had elapeed without a response. Furthermore, we used a different experimental chamber, laborntory setting, type of pigeon, pair of $\mathrm{Es}$, size and impedance of loudspeaker, click and noise generator, click setting, noine levels, and discrimination and nondifferential training procedure.

\section{Method}

Subjects The So were eight experimentally naive female silver King pigeons (5-8 years old), maintained at $75 \%$ of their free-feeding weiphts.

Apparatus. The apparatus included a Lehigh Valley Electronics pigeon test chamber (Model 1519), which was equipped with a food magazine, speaker (Quam 3.5-in. dynamic loudopeaker, 3.2 ohms impedance), houselight, and response key transilluminated by red light. Reinforcement consisted of $3 \mathrm{sec}$ access to mixed grain. The response key was dark while grain was available to $S$. As in Experiments 1 and 2, the click stimuli were produced by a Foringer click generator. However, a new unit was used in Experiment 3. During generalization tests, 11 frequencies were presented: $0.0,0.6$, $1.8,2.6,4.4,6.6,9.4,14.4,22.6$, 36.4 , and 50.2 pps. These values were close to, but not exactly the same as, the ones used in Experiment 2. The physical intensity of the clicks (approximately 91 dB SPL, superimposed on a continuous white noise of $86 \mathrm{~dB}$, messured with a General Radio Type 1551-B sound level meter at a point $10 \mathrm{~cm}$ in front of the response key with the door of the chamber closed) changed very little as click rate was varied. The noise generator was, as in Experiments 1 and 2, a Grason-Stadler Type 901B white noise generator. Three human judges reported informally that the clicking stimulus seemed to change from a succession of single pulses to a "buzz" at approximately 23-36 pps.

Procedure. The birds were initially trained to peck the key for CRF, as in Experiments 1 and 2. Following CRF training, all Ss received 11-14 60-min sessions, during which the 1.8-pps click was on continuously and keypecking was reinforced on a 1-min VI schedule.

Following this nondifferential VI training, five birds were trained on a 
successive discrimination with $\mathrm{S}+$ (1.8 pps) and $\mathrm{s}-(0.0 \mathrm{pps}$, the absence of clicks). Reinforcement of keypecking occurred on a 1-min VI schedule in $\mathbf{8 +}$ and keypecking was not reinforced in $8-$. Sessions consisted of $15 \mathrm{~S}+$ periods alternated with $15 \mathrm{~S}$ periods. The $8+$ periods always lasted $120 \mathrm{sec}$, but S- periods could last longer than 120 sec if $S$ responded in the final $30 \mathrm{sec}$ of the scheduled 120-sec period. Each response in the final 30 sec of $\mathbf{S}$ - reset a timer, 80 that S- would terminate only after $30 \mathrm{sec}$ had elapeed without a keypeck. This correction provision $\mathbf{w a s}$ included to prevent responses in 8 - from being accidentally reinforced by the appearance of $\mathbf{S +}$. Discrimination training continued until $S$ achieved two sessions (not necessarily consecutive) during which its response rate in 8 - was not more than $25 \%$ of its rate in $8+$ (this calculation was based on data for only the firmt 90 sec of $8+$ and $S-$ periods).

After the initial 11-14 nondifferential training other three birds received additional sessions ( 30 .min) on the nondifferential procedure. For a particular 8 , nondifferential training continued for a number of seasions approximately equal to that of an arbitrarily matched discrimination $\mathbf{S}$.

Finally, after a brief warm-up of additional training with reinforcement in $S+10 \mathrm{~min}$ of $\mathrm{St}$ for the nondifferentially trained $S_{c}$ and five $S+5$ and five $8-b$ for the discrimination trained Ss), a generalization test was administered in extinction. The test consisted of 11 different click frequencies, presented once in each of 12 randomized blocks. Five different sequences of the 132 test trials were used; all discrimination $\mathbf{S s}$ received a different sequence, as did all nondifferential Ss. Stimulus periods lasted 30 sec, and, as in training, there were no blackouts between test stimuli.

\section{Results and Discussion}

Individual gradients are shown in Fig. 4. As in Experiment 1, the nondifferentially trained birds (top row of Fig. 4) yielded relatively flat and unsystematic gradients, except perhaps for a slight response decline at the higher click frequencies. All five of the discrimination birds showed a peak shift, i.e., there was a gradient peak not at $S+$ but at a frequency one or two steps higher than St. In three or four of these Ss, a second peak occurred in the vicinity of $14.4 \mathrm{pps}$, which corresponds to the click value at which most of the comparably trained Ss in Experiments 1 and 2 displayed $a$ second peak.
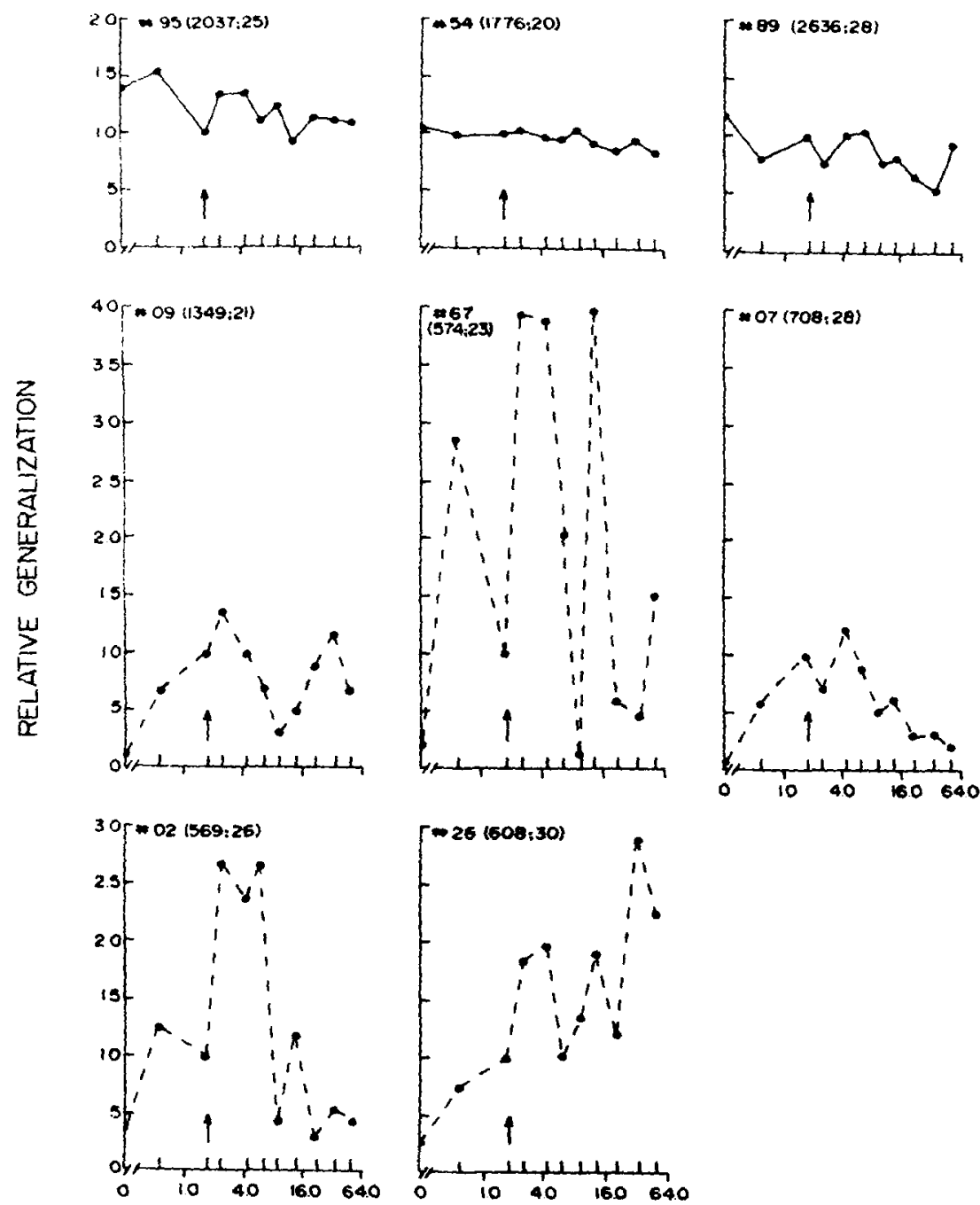

\section{CLICK FREQUENCY (PPS)}

Fis. 4. Relative generalization gradients for birds trained with $S+(1.8 \mathrm{pps})$ in Experiment 3. Birds in the top row received nondifferential training; birds in the bottom two rows were trained on a successive discrimination with $s-$ the absence of clicks $(0.0 \mathrm{pps})$. For each $S$, the first number in parentheses is the total number of pecks during the test and the second number is the number of training sessions following the initial 11-14 1-h sessions of nondifferential training.

Therefore, in spite of the numerous methodological changes instituted in this experiment, the main characteristics of the gradients that had been obtained from the discrimination and nondifferential Ss of Experiments 1 and 2 (with $S+$ of $1.6 \mathrm{pps}$ ) were replicated in Experiment 3.

\section{EXPERIMENT 4}

Experiment 4 was designed to provide additional information about click-frequency effects, especially the phenomenon of peak shift along this dimension. Pigeons were trained on discriminations that involved two above-zero click frequencies. In some birds, the $\mathrm{s}$ - frequency was lower than $\mathbf{S}+$, whereas in other birds it was higher. Therefore, the opportunity existed to observe peak shift toward either the higher or lower frequencies. In Experiments 1-3, the absence of clicks (0.0 pps) served as $\mathrm{S}$ - for all discrimination Ss, and therefore peak shifts toward only the higher frequencies could have been observed. If a peak shift were obtained in both directions on the click dimension, one would feel more confident that it was determined by essentially the same behavioral mechanisms as those producing peak shift in experiments 

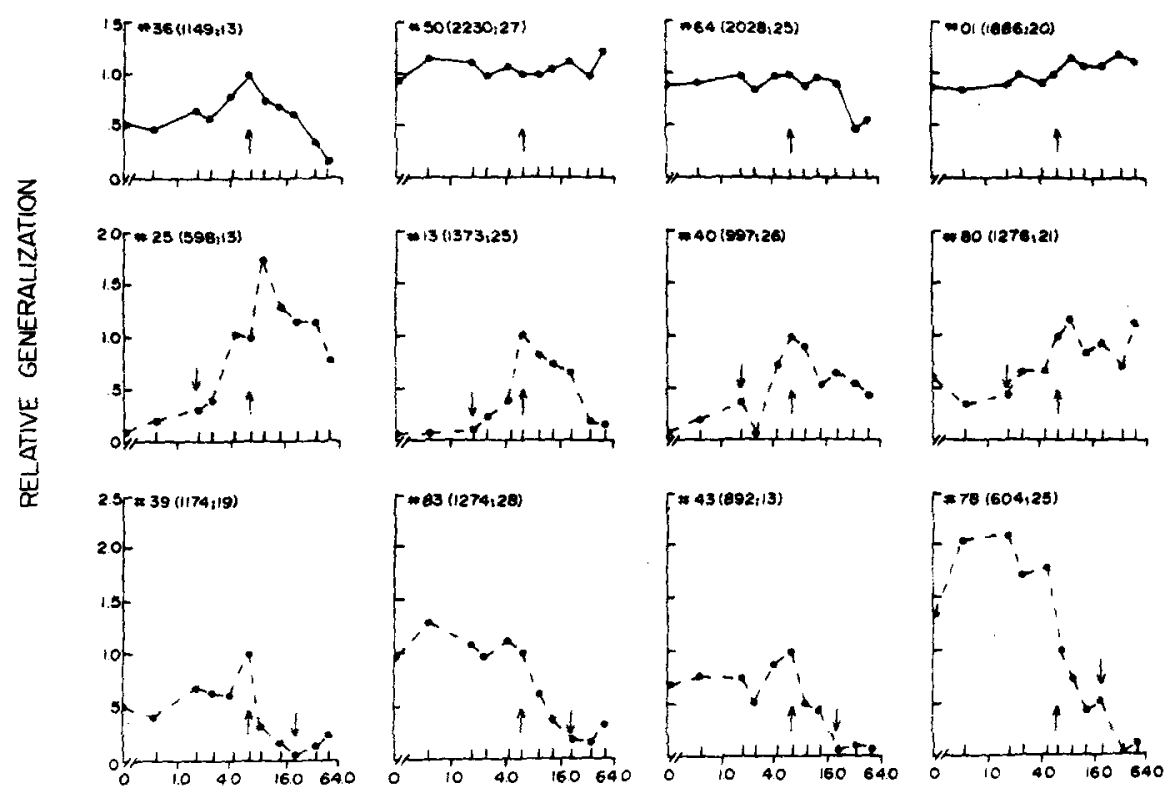

\section{CLICK FREQUENCY (PPS)}

Fig. 5. Relative generalization gradients for birds trained with $S+(6.6 \mathrm{pps})$ in Experiment 4. Birds in the top row received nondifferential training; birds in the second row received successive discrimination training with $S-(1.8$ pps); and birds in the bottom row received successive discrimination training with $S-$ (22.6 pps). Numbers in parentheses are as in Fig. 4. Upward arrows indicate $\mathbf{S}+$, downward arrows $\mathbf{S}$. Four different generalization test sequences were used, and all birds in the same column received the same test sequence.

with visual wavelength. That is, the presumed peak shifts found in Experiments 1-3 could not have been due merely to some unknown intensitive or "perceptual" effect peculiar to the click dimension.

\section{Subjects and Apparatus}

Twelve experimentally naive female Silver King pigeons (5-8 years old) were maintained at $75 \%$ of their free-feeding weights. The apparatus was the same as in Experiment 3.

\section{Procedure}

Four birds were trained on a successive discrimination involving $\mathbf{S +}$ (6.6 pps) vs S- (1.8 pps), four were trained with $S+(6.6 \mathrm{pps})$ vs $\mathrm{S}-$ (22.6 pps), and four were given nondifferential VI training with a continuous 6.6-pps click. All other details of training and testing were the same as for the comparable treatments in Experiment 3.

\section{Results and Discussion}

Individual gradients are shown in Fig. 5. Among the nondifferentially trained birds (top row), one (No. 36) displayed good evidence of specific control by the click value continuously present during training. This S's gradient had a distinct peak at the $\mathrm{S}+$ value and is the only one of all the gradients of the nondifferentially trained birds $(N=13)$ in Experiments 1-4 that exhibited a relatively steep gradient around $S+$.

Among the discrimination birds, two of the four in each group showed a peak shift away from $\mathrm{S}-$. The shift is very clear in Birds 25 and 78 and less marked in Nos. 80 and 83 . The gradients of the other four discrimination birds had their maximum at S+. However, all eight birds responded much more to values on the $\mathbf{S}+$ side of the dimension than on the $S^{-}$side (distribution or area shift; see Terrace, 1966). Therefore, appropriate placement of $\mathbf{S}-$ can yield shifts in either direction along the dimension. The postdiscrimination gradients in Fig. 5 (all for an $S+$ of 6.6 pps) appear less complex and more consistent than the gradients obtained in Experiments 1.3 for an $S+$ of 1.6 or 1.8 pps.

\section{GENERAL DISCUSSION}

These experiments demonstrate that differential responding is not likely to occur during a click-generalization test unless pigeon $S s$ have previously received explicit training to discriminate one click frequency from another. This result is unlike those typically obtained along various visual dimensions (e.g., wavelength, line tilt, brightness) in pigeons that peck a key on which the various stimuli are projected; in such a situation, explicit discrimination training is usually not necenary for steep generalization gradient to emerge. Auditory stimuli, on the other hand, apparently yield different findings: our results resemble those of Jenkins and Harrison (1960), who obtained steep tonal-frequency gradients around a 1,000-Hz tone only after birds had been trained to diecriminate between a 1,000- $\mathrm{Hz}$ tone $(S+)$ and the absence of a tone $(\$-)$. However, the relationship between $\mathbf{S +}$ and $\mathbf{g}$ in Jenkins and Harrison's work seems different from ours. In their experiments, the no-tone condition was presumed to be orthogonal to the dimension of the generalization test; tone absence is no closer to any one audible tone frequency than to any other and therefore cannot be meaningfully located anywhere on the tone-frequency dimension. In our experiments, on the other hand, the no-click condition can justifiably be placed at $0.0 \mathrm{pps}$ along the click-frequency continuum.

This nonorthogonality of S+ and $S-$ probably was crucially involved in producing the peak shifts obtained in most $(12 / 17)$ of the discrimination $S$ s trained with the absence of clicks as S- (Experiments 1-3). In contrast, none of Jenkins and Harrison's birds showed peak shift; all of them responded maximally to the $S+$ value. Failure to consider the possibility that absence of clicks is not orthogonal to the dimension under study may have accounted in part for the complex and irregular click gradients occasionally obtained in rat studies, e.g., the findings of Hendry et al (1969), whose "control periods" (silent intertrial intervals occurring between a click S+ and a click S-) actually involved presentations of a stimulus ( $0.0 \mathrm{pps}$ ) that lies on the relevant dimension.

Exactly why discrimination training is apparently necessary to produce differential responding along auditory dimensions in these experiments with pigeons but is not explicitly required along several visual dimensions in the same organism remains an open question. It could depend on the ontogenetic or phylogenetic history of birds with regard to visual vs auditory stimuli, or be related to the fact that virtually all the pertinent experiments utilized a keypecking operant situation in which the visual stimuli were projected directly on the response key, whereas the auditory stimuli were necessarily rather diffuse and unlocalized (see Terrace, 1966, pp. $277 \mathrm{ff}$ ). Experiments with "diffuse" visual stimuli, or easily localized auditory stimuli, may help to determine whether there is some basic difference between visual and auditory discrimination-generalization processes 
in birds or whether the differences mentioned above are due to certain aspects of the typical experimental tasks used in operant studies.

When discrimination training involved two above-zero click values (Experiment 4), a shift in the distribution of generalization responses away from $s-$ occurred regardless of whether $\mathrm{S}-$ was lower or higher than $\mathbf{S +}$. This effect seems directly analogous to the phenomenon of area or peak shift that has previously been obtained by many investigators along visual continua. Theoretical accounts of the basic phenomenon have recently been reviewed by Hearst (1969).

An especially provocative result involves the complex but fairly reproducible gradients obtained from birds trained with $\mathrm{S}+(1.6 \mathrm{pps}$ or $1.8 \mathrm{pps})$ vs $\mathrm{S}-(0.0 \mathrm{pps})$ in Experiments 1-3. Those gradients tended to display a mode slightly above S+ (an effect which we have considered an example of peak shift) and another mode at approximately 14.2 pps. Furthermore, there was often a major decline in responding at values above 20 pps. These findings are more easily summarized than explained. However, we can briefly note a few effects that may be involved.

(1) The response decrements occurring at the three highest click values (approximately 23-54 pps) in more than half the Ss in Experiments 2-3 could conceivably reflect some qualitative change in the auditory stimulus, corresponding to what human Ss report as a change from a succession of single pulses to a low-frequency buzz. As noted earlier, in informal judgments, five human Os reported that the click stimuli produced by a Foringer generator seemed to change from a succession of single pulses to a buzz at approximately 25-35 pps. An alternative explanation of the response declines at the highest frequencies might posit some aversive quality to high-frequency clicks. However, the latter alternative seems unlikely because there was little evidence of such decremental effects in the nondifferentially trained Ss of Experiments 3 and 4.

(2) "Intensity-like effects" may be interacting with click-frequency control along the dimension. Human Ss generally report loudness increments as the frequency of periodic auditory pulses is increased. Although the gradient-interaction analysis offered by Perkins and Logan to handle stimulus intensity dynamism in a variety of behavioral situations is compatible with certain features of our complex gradients, i.e., peak shifts followed by response declines as click frequency increases, it apparently cannot handle the fact that responding eventually recovers at a specific value(s) far above S+.

(3) The bimodal or multimodal gradients obtained in our work are reminiscent of similarly shaped generalization gradients for pitch obtained by, for example, Blackwell and Schlosberg (1943). Perhaps there is some way in which these two kinds of frequency-generalization gradients can be theoretically integrated.

In any case, comparisons of the present results with those from human studies of flutter-frequency perception remain dubious because (1) subhuman studies have mainly involved generalization procedures rather than threshold determinations (the latter psychophysical methods would naturally yield much more precise measures of discriminative capacity and response bias); (2) the amount of prior experience in making discriminations along the interruption-rate dimension is hard to equate for humans vs subhumans; (3) the signal-noise ratio and the absolute decibel levels typically employed in animal work are different from and usually less well-controlled than those used in human studies; and (4) click stimuli in the present studies remained on for $30 \mathrm{sec}$ or more, whereas in human research, the click trains are typically very short. The systematic importance of these discrepancies will have to be evaluated by further animal and human experimentation.

\section{REFERENCES}

BLACKWELL, H. R., \& SCHLOSBERG, H. octave ceneralization, pitch discrimination, and loudness thresholds in the white rat. Journal of Experimental Psychology, 1943, 33, 407-419.

BLOUGH, D. S. Generalization and preference on a stimulus-intensity continuum. Journal of the Experimental Analysis of Behaviox, 1959,2,307-317.

CRITES, R. J., HARRIS, R. T., ROSENQUist, H., THOMAS, D. R. Response patterning during stimulus generalization in the rat. Journal of the Experimental Analy ds of Behavior, 1967. 10, 165-168.

ERNST, J. A., ENGBERG, L., THOMAS, $D$. R. On the form of stimulus generalization curves for visual intensity. Journal of the Experimental Analysis of Behavior, 1871, 16, 177-180.

FLANAGAN, J. L.. GUTTMAN, N. On the pitch of periodic pulses. Journal of the Acoustical Society of America, 1960 32, 1308-1319.

GRAY, J. A. Stimulus intensity dynamism. Psychological Bulletin, 1965, 63, 180-196.

HEARST, E. Approach, avoidance, and stimulus generalization. In D. Mostofsky (Ed.), Stimulus generalization. Stanford: Stanford University Press, 1965. Pp. 331-355.

HEARST, E. Excitation, inhibition, and discrimination learning. In $\mathbf{N}$. $J$ Mackintosh and W. K. Honig (Eds.), Fundamental issues in associative learning. Halifax, Canada: Dalhousie University Press, 1969. Pp. 1-41.

HENDRY, D. P., SWITALSKI, R., \& YARCZOWER, M. Generalization of conditioned suppression after differential training. Journal of the Experimental Analysis of Behavior, $1969,12,799-806$.

HULL, C. L. Stimulus intensity dynamism (V) and stimulus generalization. Psy chological Review, 1949, 56, 67-76.

JENKINS, H. M., \& HARRISON, R. H. Effect of discrimination training on auditory generalization. Journal of Experimental Psychology, 1960, 59 246-253.

LOGAN, F. A note on stimulus intensity dynamism (V). Psychological Review, $1954,61,77-80$.

MALOTT, R. W., \& MALOTT, M. K A preliminary analysis of loudness in terms of stimulus generalization. Paper presented at the meeting of the Psychonomic Society, Chicaro, 1967

MILLER, G. A., TAYLOR, W. G. The perception of repeated bursts of noise. Journal of the Acoustical Society of America, 1948, 20, 171-182.

MOSTOFSKY, D. I. SHURTLEF, D. A. \& MARGOLIUS, G. Comparative senvitivity of rats and humans to changes in auditory click rate. Jourmal of Comparative \& Physiological Psychology, $1964,58,436-440$

PAVLOV I. P. Conditioned reflexes. London: Oxford University Press, 1927. PERKINS, C. C. The relation between conditioned stimulus intensity and response strength. Journal of Experimental Psychology, 1953, 46. 225-231.

POLLACK, I. On the threshold and loudness of repeated bursts of noise. Journal of the Acoustical Society of America, 1951, 23, 646-650.

POLLACK, I. Auditory flutter. American Journal of Psychology, 1952, 65. 544-564.

RILEY, D. A., \& LEUIN, T. C. Stimulus-generalization gradients in chickens reared in monochromatic light and tested with a single wavelength value. Journal of Comparative \& Physiological Psychology, 1971, 75, 399-402.

SIDMAN, M. Stimulus generalization in an avoidance situation. Journal of the Experimental Analysis of Behavior, 1961 4, 157-169.

STEVENS, J. C.. \& shickMAN, G. M. The perception of repetition rate. Joumal of Experimental Psychology, 1959, 58, 433-440.

TERRACE, H. S. Stimulus control. In W. $K$. Honig (Ed.), Operant behavior: A reas of research and application. New York: Appleton-Century-Crofts, 1966 . Pp. 271-344

WINOGRAD, E. Maintained ceneralization testing of conditioned suppression Journal of the Experimental Analysis of Behavior, 1965, 8, 47-51.

(Accepted for publication April 5, 1972.) 